\title{
Knowledge, awareness and acceptability of anti-HPV vaccine in the Arab states of the Middle East and North Africa Region: a systematic review
}

Rihab Gamaoun ${ }^{1}$

${ }^{1}$ Faculty of Pharmacy, University of Monastir, Monastir, Tunisia (Correspondence to: Rihab Gamaoun: rihab.gamaoun@outlook.com).

\begin{abstract}
Background: Rapid changes in lifestyle induced by globalization have brought about changes in sexual behaviour, especially among younger generations. These changes may lead to considerable consequences on the prevalence of sexually transmitted disease, including human papillomavirus (HPV) infection.
\end{abstract}

Aims: The objective of this study is to provide a systematic review of peer-reviewed literature on human papillomavirus (HPV) vaccine awareness and acceptability in the Arab states of the Middle East and North Africa region.

Methods: A systematic search was conducted across 2 electronic databases: PubMed and EMBASE, to identify studies related to HPV vaccination awareness and acceptability in the region between January 2010 and April 2017.

Results: Eighteen studies from 9 countries were identified. The analysis showed low to moderate HPV infection knowledge and anti-HPV vaccine awareness. Nevertheless, most studies reported moderate to high anti-HPV vaccine acceptability among subpopulations. Broad gaps in knowledge and willingness were highlighted regarding HPV vaccine acceptability.

Conclusions: An examination of the region collectively offers an insight into the willingness of the general population and healthcare providers to receive more information about the virus and prevention of infection through vaccination. This review suggests that the vaccine acceptability would be high once cost concerns are resolved.

Keywords: HPV, awareness, vaccine, Middle East, North Africa.

Citation: Gamaoun R. Knowledge, awareness and acceptability of anti-HPV vaccine in the Arab states of the Middle East and North Africa region: a systematic review. East Mediterr Health J. 24;2018(6):538-548. https://doi.org/10.26719/2018.24.6.538

Received: 016/10/5; accepted: 17/06/18

Copyright (C) World Health Organization (WHO) 2018. Some rights reserved. This work is available under the CC BY-NC-SA 3.o IGO license (https:// creativecommons.org/licenses/by-nc-sa/3.o/igo).

\section{Introduction}

The Arab world stretches from Morocco to Saudi Arabia, and is characterized by societies sharing relatively comparable cultures and religious conservatism. This implies more conservative sexual behaviours than in other cultures (1). Given this particular cultural context, the prevalence of sexually transmitted infections [including human papillomavirus (HPV)] has previously been reported to be low in this region compared to rest of the world (2). That said, given the rapid changes in lifestyle induced by globalization, sexual behaviour, especially among younger generations, is changing: practices are much more liberal than what was accepted during previous decades. These changes may induce considerable consequences on the prevalence of sexually transmitted diseases, even in this region (1).

The incidence of cervical cancer has been reported as 6.4 per 100000 in the North Africa region and 3.4 per 100000 in the Greater Middle East $(3,4)$. Although difficult to evaluate precisely because of the absence of cancer registries, cervical cancer rates are estimated to be lower in this region than in the rest of the world. This partly explains the delay seen in establishing national cervical cancer prevention programmes in this region (5).

Despite the inaccurate incidence estimates, cervical cancer is the second most common cancer among women in Algeria and Morocco (after breast cancer) and the third most common in Tunisia, Oman and United Arab Emirates (3). In the extended Middle East and North Africa (MENA) region (excluding Pakistan), cervical cancer is ranked as the fourth most common cancer, with 7949 new cases estimated in 2008 (4.4\% of all cancers in the region) (5).

Based on these statistics, and despite the relatively low incidence, cervical cancer is still a public health issue in the Arab states. Because of the proven causal link between HPV infection and the development of cervical cancer, the introduction of an effective and safe antiHPV vaccine is an excellent opportunity to eradicate this devastating preventable disease as well as other HPVrelated diseases in the Arab MENA states, as elsewhere in the world (6).

In June 2006, the first vaccine against HPV was approved by the Food and Drug Administration of the United States of America for the primary prevention of cervical cancer. Today, 2 prophylactic vaccines against HPV are currently registered: bivalent Cervarix (GlaxoSmithKline, Belgium) and quadrivalent Gardasil (Merck and Co., Inc., United States of America) (7). Both vaccines are well tolerated with good profiles for efficacy 
in preventing HPV infection (6). The vaccine against HPV has gained rapidly in popularity in many countries and it has been licensed in over 150 countries around the world (8).

Despite the availability of the vaccine, national programmes implementing HPV vaccination are very rare in the Arab states: only 1 country (United Arab Emirates) has effectively introduced the vaccine through a national programme and very few others have planned to introduce it in the near future (8).

Several factors have influenced the slow introduction of the anti-HPV vaccination in the region: financial constraints, poor infrastructure for adolescent vaccine delivery, competition with high-priority vaccines and the lack of reliable data on the burden of HPV diseases (8-10). However, the main obstacle to an effective introduction of the anti-HPV vaccine is still the low political will that is often justified by cultural and religious sensitivities, which could limit the success of such vaccination programmes (11).

The experience of the United Arab Emirates also revealed a high overall absorption of the vaccine in the first year of introduction (77\%). This then declined to 59\% in $2010 / 2011$, probably because of the unfounded media campaign fueling the controversy surrounding the possible adverse effects of the vaccine (8).

In this study, we aimed to assess the knowledge and awareness of HPV infection and anti-HPV vaccine, the acceptability of the vaccine and the willingness to receive or recommend the vaccine in the Arab states of the MENA region through a systematic review of the peer-reviewed literature. We chose to restrict our search to only the Arab states of the region to enhance the generalizability of our results to all countries of this region with similar cultural and religious background.

\section{Methods}

\section{Identification of studies}

Studies assessing the knowledge and acceptability of anti-HPV vaccine in Arab states of the MENA region were identified by searching for studies in 2 databases (PubMed and Embase) published between 1 January 2010 and 10 April 2017.

The search was conducted using the key term "HPV vaccine" in addition to all terms describing the geographic and cultural area of interest (keywords were: Algeria, Bahrain, Egypt, Iraq, Jordan, Libya, Kuwait, Lebanon, Mauritania, Morocco, Oman, Qatar, Saudi Arabia, Sudan, Syria, Tunisia, United Arab Emirates and Yemen).

\section{Inclusion criteria}

All the included studies met the following criteria:

- conducted in at least 1 of the Arab states of the MENA region,

- had considered at least 1 of the themes: <list2>

- HPV infection knowledge,

- HPV-cervical causal association knowledge,
- anti-HPV vaccine awareness

- willingness to receive the vaccine or to get daughter vaccinated.

\section{Search strategy}

All literature relating to HPV vaccination in the Arab states of the MENA region was sought and the search consisted of database-specific vocabulary and use of Boolean operators for: HPV vaccine AND (Sudan OR Mauritania OR Morocco OR Algeria OR Tunisia OR Libya OR Egypt OR Lebanon OR Syria OR Iraq OR Jordan OR Bahrain OR Qatar OR Saudi Arabia OR Yemen OR Kuwait OR United Arab Emirates OR Oman). Date restriction was employed for the period 01 January 2010-10 April 2017 to exclude old studies published during the first years of commercialization of the HPV vaccine. A language restriction was employed to capture only publications in English and French, the 2 main languages of scientific publications in the region of interest. The complete search strategy is presented in Figure 1.

\section{Study selection}

The search was narrowed to identify studies that involved the examination of HPV vaccine acceptability and knowledge or attitudes related to HPV vaccines in the Arab states of the MENA region.

No limit was placed on the types of study participants, all subpopulations were considered: women, parents, males, healthcare professionals and students. No limit was placed on study design, however, included articles were required to report original data (i.e. not reviews, editorials or commentary).

Titles and abstracts of all articles returned from the initial search were screened and those which were irrelevant (irrelevant geographic area, literature reviews, HPV prevalence, HPV genotype distribution, case studies, cost-effectiveness studies, etc.) were excluded (n $=67$ articles). The remaining articles were given full-text review and further exclusions were made if they did not meet the inclusion criteria. The articles were examined by 2 reviewers to confirm that inclusion criteria were satisfied and to reach consensus when necessary.

Overall, most of the studies had been properly conducted except 2 papers issued by the same author and based on the same data, but reporting nonconcordant results for the same assessed outcomes. The full-text screening led to the exclusion of 13 more articles for noneligibility (10 eligibility criteria unmet, 2 articles based on the same study with nonconcordant results and 1 nonaccessible article). A total of 18 studies were retained (Figure 1).

\section{Data abstraction and analysis}

A systematic review of publications of interest was performed summarizing the main results; these were subsequently treated as primary data.

Adata abstraction form was created after a preliminary scan of the relevant literature and data abstraction 
was conducted by one of the reviewers involved in the selection of studies. Abstracted data were oganized by key information such as study population, sample size and main conclusions on the levels of HPV and HPV vaccine knowledge, awareness and willingness to receive or to recommend the vaccine.

Awareness, knowledge and acceptability levels were divided into 4 categories: HPV knowledge, association between HPV and cervical cancer awareness, HPVvaccine awareness and willingness to get vaccinated or to vaccinate daughters.

Factors influencing HPV knowledge and antiHPV-vaccine acceptability were reported to provide a qualitative overview for a better understanding of the improvement opportunities of the acceptability of antiHPV vaccination.

\section{Results}

\section{Overview of the reviewed studies}

The 18 studies reviewed involved 9 Arab states of the MENA region: 6 studies were conducted on healthcare clinicians or students; 3 involved parents; 7 involved women of different age groups; 1 involved adolescents and young adults and 1 involved a group of young men (Table 1).

\section{Knowledge and awareness of the HPV infection}

Nine of the selected studies examined HPV infection knowledge by asking if (yes or no) participants had already heard about HPV infection and/or were satisfied with the information they had received.

Prevalence varied between $4.2 \%$ and $97.0 \%$ depending on the country and subpopulation. It was highest among the subgroup healthcare professionals (97.0\%) and lowest among the subgroup of parents (ranging between $4.2 \%$ and $18.0 \%$ ). Knowledge of HPV infection ranged between $31.0 \%$ and $65.0 \%$ among women, $20.0 \%$ among adolescents and $31.0 \%$ among males (Table 2).

\section{Knowledge and awareness of the causal link HPV infection-cervical cancer}

Ten of the reviewed studies had examined the HPV-cervical cancer association awareness. Prevalence varied be-

Figure 1 Data flow diagram of the complete search strategy

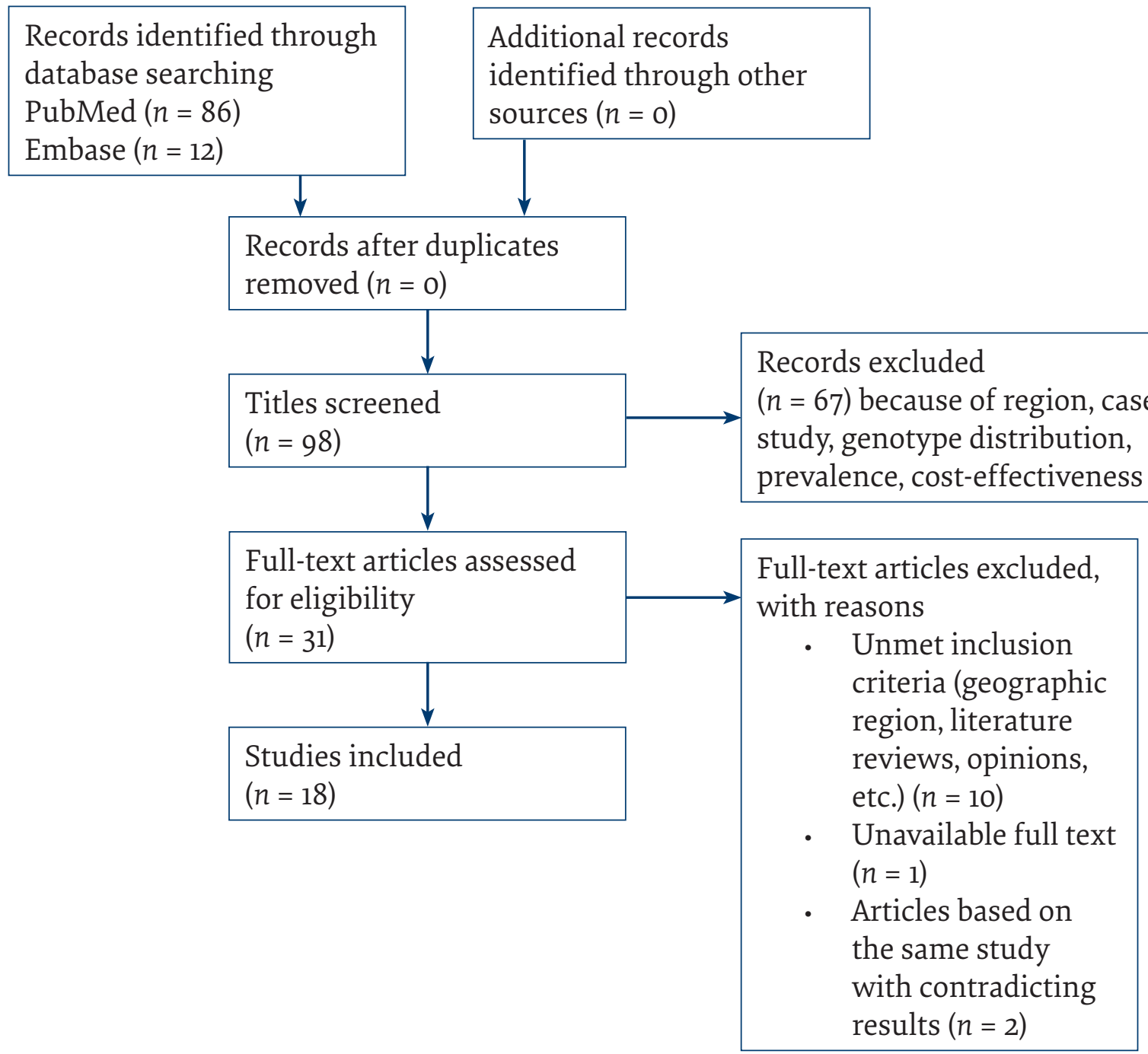




\begin{tabular}{|c|c|c|}
\hline \multicolumn{3}{|c|}{$\begin{array}{l}\text { Table } 1 \text { Descriptive summary of the studies retained in the } \\
\text { review }\end{array}$} \\
\hline Category & No. & Reference \\
\hline Total no. of studies & 18 & - \\
\hline Total no. of countries & 9 & - \\
\hline Bahrain & 1 & 19 \\
\hline Egypt & 1 & 20 \\
\hline Jordan & 1 & 21 \\
\hline Lebanon & 1 & 13 \\
\hline Morroco & 4 & $14,22-24$ \\
\hline Saudi Arabia & 5 & $25-29$ \\
\hline Syrian Arab Republic & 1 & 30 \\
\hline Sudan & 1 & 31 \\
\hline United Arab Emirates & 3 & $12,15,16$ \\
\hline \multicolumn{3}{|l|}{ Demographics of studies } \\
\hline Women & 7 & $13,16,19,20,25,26,31$, \\
\hline Parents & 3 & $14,23,30$ \\
\hline Men & 1 & 15 \\
\hline Healthcare clinicians \& students & 6 & $12,21,22,27-29$ \\
\hline Adolescents and young adults & 1 & 24 \\
\hline Knowledge and awareness of HPV & 9 & \\
\hline Reported prevalence $>80 \%$ & 1 & 12 \\
\hline Reported prevalence $30-80 \%$ & 5 & $15,16,19,20,26$ \\
\hline Reported prevalence $<30 \%$ & 4 & $14,23,24,29$ \\
\hline $\begin{array}{l}\text { Awareness of causal link HPV } \\
\text { infection-cervical cancer }\end{array}$ & 10 & \\
\hline Reported prevalence $>80 \%$ & 3 & $12,13,22$ \\
\hline Reported prevalence $30-80 \%$ & 4 & $25,27,28,31$ \\
\hline Reported prevalence $<30 \%$ & 3 & \\
\hline $\begin{array}{l}\text { Knowledge and awareness of anti- } \\
\text { HPV vaccine }\end{array}$ & 9 & \\
\hline Reported prevalence $>80 \%$ & 1 & 12 \\
\hline Reported prevalence $30-80 \%$ & 6 & $13,22,26,28-31$ \\
\hline Reported prevalence $<30 \%$ & 2 & 14,21 \\
\hline Acceptability of anti-HPV vaccine & 11 & \\
\hline Reported prevalence $>80 \%$ & 4 & $16,19,20,25$ \\
\hline Reported prevalence $30-80 \%$ & 6 & $12,14,15,23,26,29$ \\
\hline Reported prevalence $<30 \%$ & 1 & 24 \\
\hline
\end{tabular}

$\mathrm{HPV}=$ human papillomavirus.

tween $8.4 \%$ and $95.1 \%$ depending on the country and subpopulation. Prevalence was highest among the subgroup females, ranging between $27.4 \%$ and $81.9 \%$, and lowest among the subgroup of parents (8.4\%). Among healthcare professionals and students, the prevalence ranged between $45.0 \%$ and $95.1 \%$ (Table 2 )

\section{Anti-HPV vaccine awareness}

Nine of the selected studies examined anti-HPV vaccine awareness. Prevalence varied between $14.2 \%$ and $97.0 \%$. The highest prevalence was found among the subgroup healthcare professionals and students ranging between
27.2\% and 97.0\%. The lowest prevalence was found among the subgroup parents ranging from $14.2 \%$ to $34.2 \%$. Among females, the prevalence ranged between $32.3 \%$ and $63.5 \%$ (Table 2).

\section{Anti-HPV vaccine acceptability}

Eleven of the selected studies examined anti-HPV vaccine acceptability by asking whether participants would accept to receive the vaccine or to get their daughters vaccinated. Prevalence varied between $20.4 \%$ and $99.0 \%$. The highest prevalence was among the subgroup females, ranging between $46.0 \%$ and $99.0 \%$. The lowest prevalence was among the subgroup adolescents and ranged between $20.4 \%$ and $62.0 \%$. The acceptability prevalence was around $46.0 \%$ among males and it ranged between $50 \%$ and $74 \%$ among healthcare professionals and students (Table 2).

\section{Factors associated with the acceptability of anti-HPV vaccine}

Several studies discussed factors possibly influencing vaccine acceptability. The main barriers to acceptability of the vaccine included:

- cultural barriers, reported especially by nurses who found it difficult to address the issue of vaccination with parents (12),

- high costs $(13,14)$.

In terms of factors improving the acceptability of the vaccine, the following were reported:

a high socioeconomic level generally (14),

clear recommendations from the authorities or medical professionals about the effectiveness and safety of the vaccine (implying better information) (14),

the desire to become protected again HPV and to protect a partner (15).

\section{Strategies for introduction of anti-HPV vaccine}

Among the 18 studies retained in this review, 3 were conducted in the United Arab Emirates, the only country that had already introduced a national programme of HPV vaccination. In 2008, the Health Authority of Abu Dhabi (the capital of the United Arab Emirates) introduced the free anti-HPV vaccine for schoolgirls, whether or not they were natives of the United Arab Emirates; becoming the first country in the MENA region to organize a national cervical cancer immunization programme $(12,15,16)$.

Regarding the 8 other countries included in this review, they had all previously introduced at least 1 of the 2 available vaccines, but none had issued clear recommendations about the vaccine or planned for a national immunization programme except Morocco (8). In fact, since 2011, a programme of national immunization was proposed for all girls aged 11 years by Moroccan authorities. However, this programme is still in its pilot phase.

Most of the studies covering cervical cancer awareness and screening interventions highlighted the 


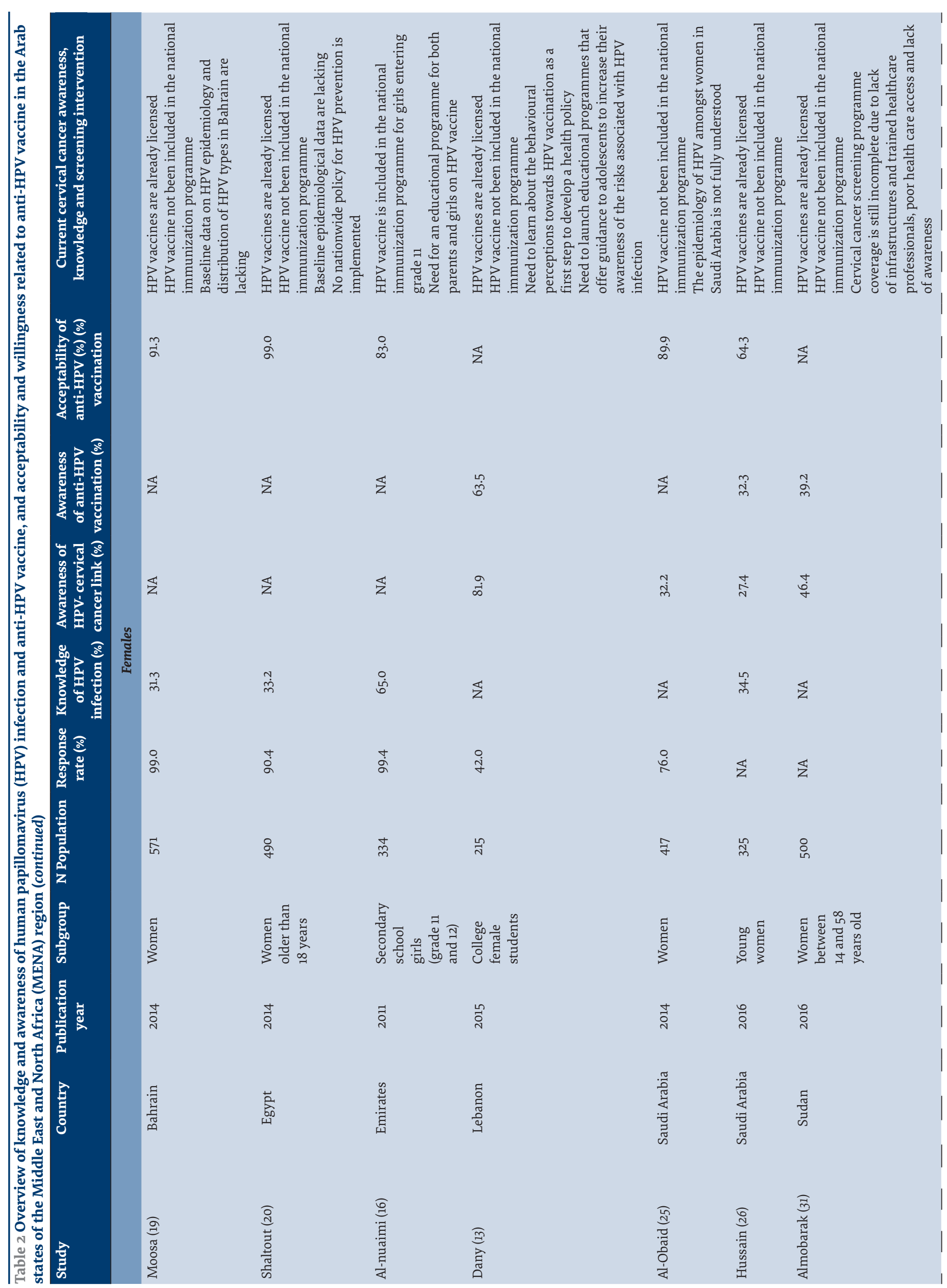




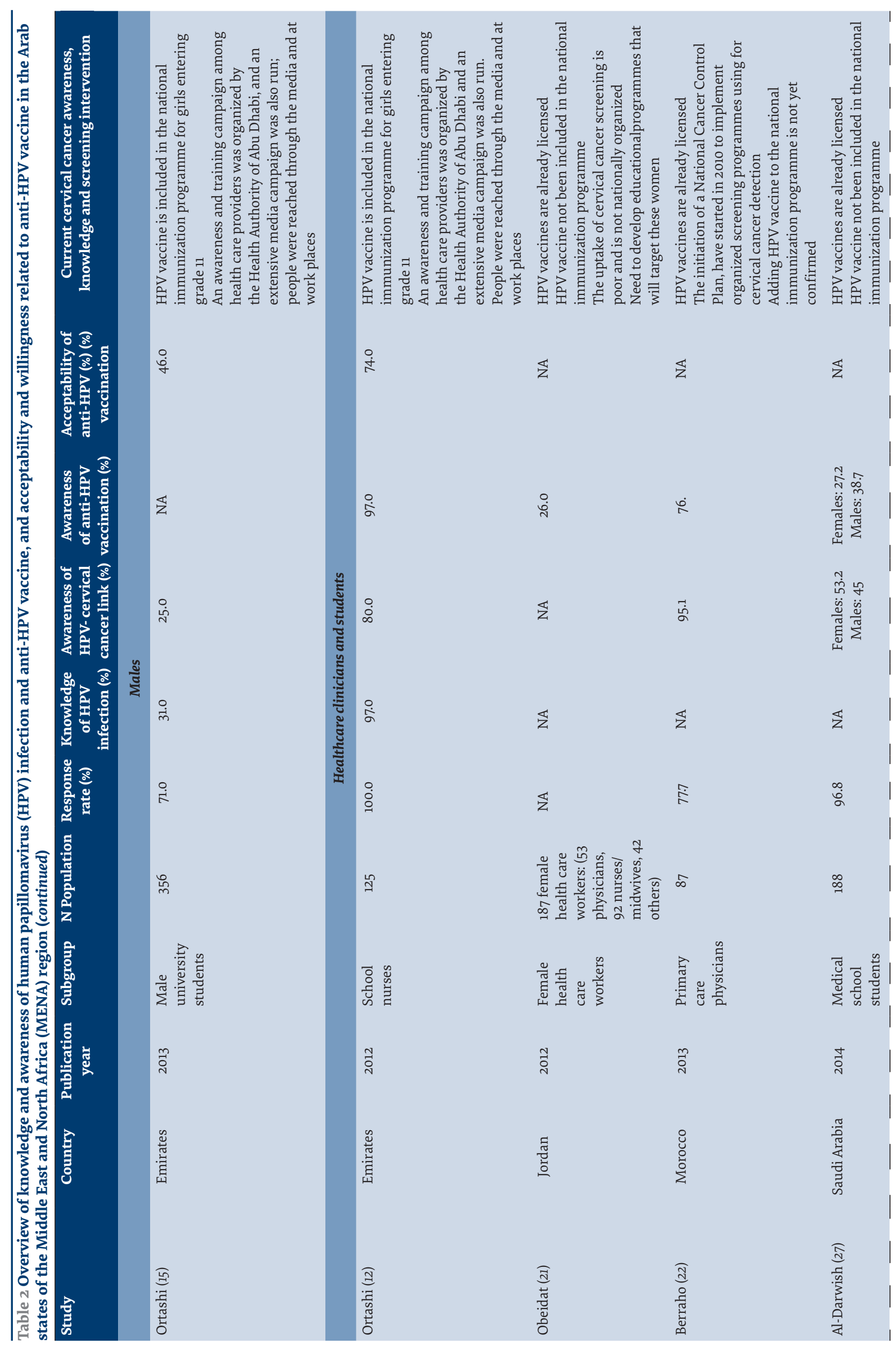




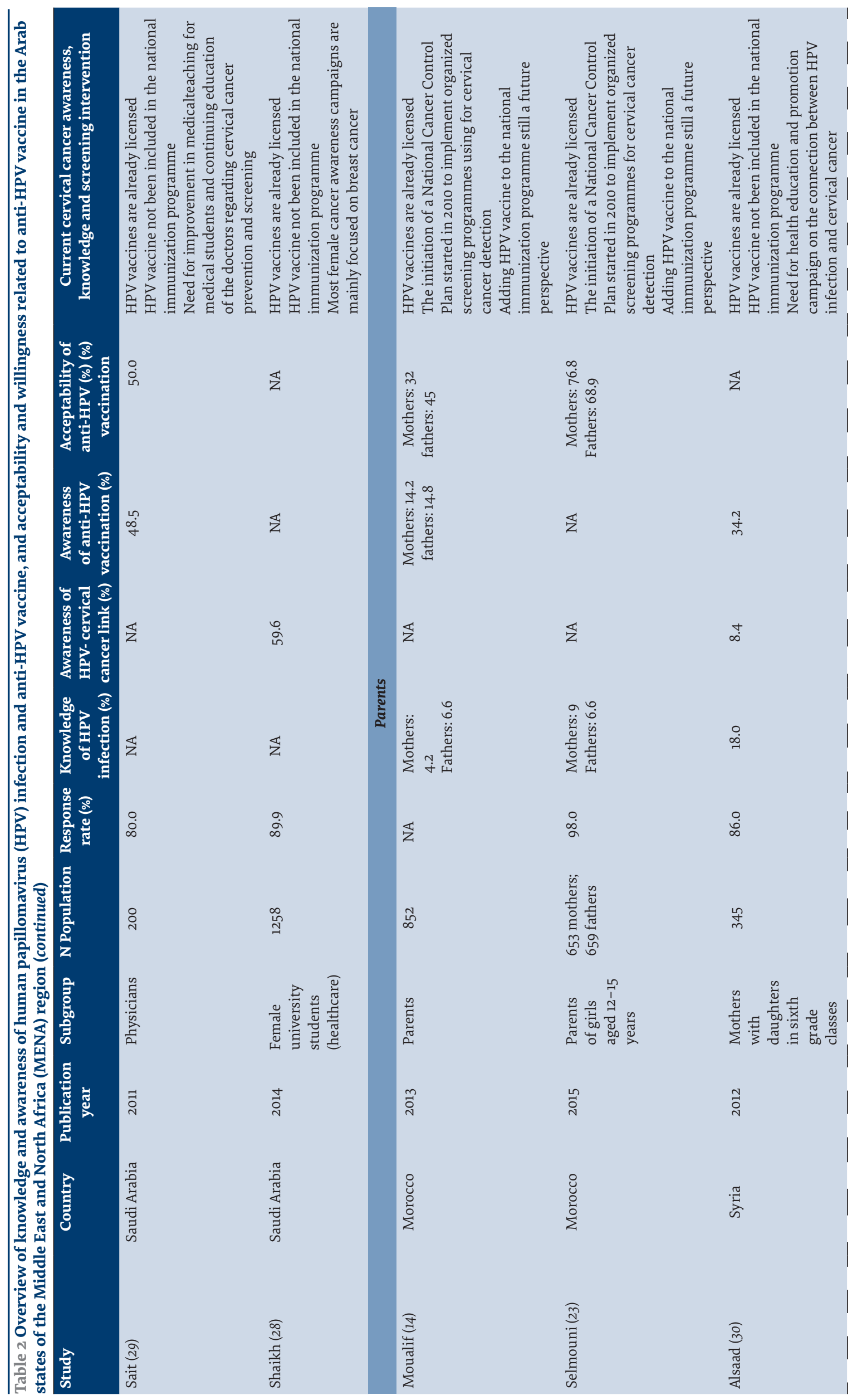




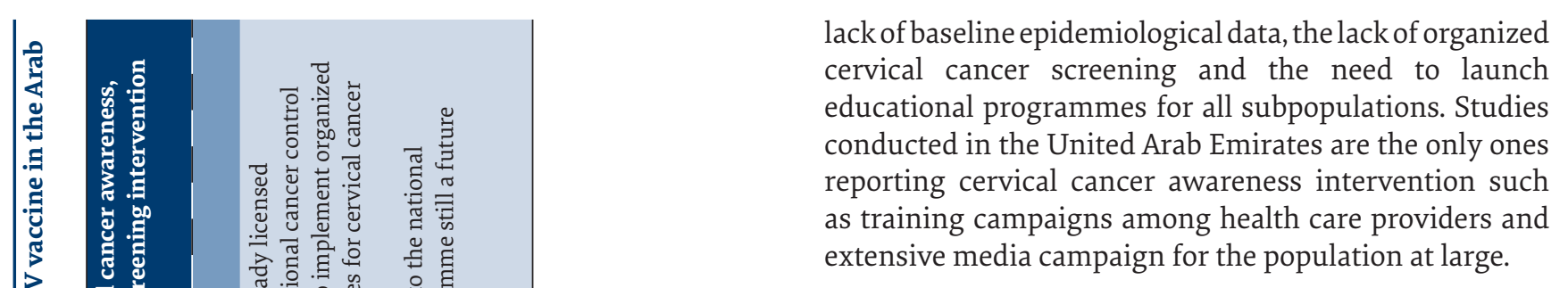

\section{Discussion}

This review revealed low to moderate knowledge of HPV infection and anti-HPV vaccine awareness; nevertheless, it showed moderate to elevated levels of anti-HPV vaccine acceptability among the various demographic groups studied.

What is interesting in our findings is that despite the lack of knowledge about HPV, its causal relationship with cervical cancer and the availability of the vaccine, a strong interest in learning more about the vaccine was identified along with a strong willingness to become vaccinated or to get daughters vaccinated.

These results convey a real opportunity for education and awareness strategies about HPV and cervical cancer. In addition, the cultural barrier that seems to be the main justification for the lack of political will to engage in national cervical cancer prevention seems unfounded.

Based on our findings, information on and public sensitization to HPV, its seriousness, potential complications, challenges and the assurance of effectiveness of the vaccine would improve the acceptability of such a vaccine (11). In addition, studies conducted in the only country that already has a national programme showed that the cultural barrier was mentioned by only $18 \%$ of participants, demonstrating that this reason is not among the principal barriers (15).

These results revealed an opportunity for countries wishing to set up a vaccination programme, and where cervical cancer is considered a public health problem. Our findings indicate that education strategies and interventions aimed at increasing awareness and knowledge about HPV and the anti-HPV vaccine would be in accordance with public expectations and would optimize the acceptability of the vaccine.

In addition, qualitative insights provided by this review showed that the factors influencing acceptability are often related to public trust issues such as concerns about side-effects and safety (17).

Training and education would also need to be provided for health care professionals, especially health care students, since this subgroup reported average antiHPV acceptability. Recognizing the major importance of these current and future clinicians in terms of cervical cancer awareness and screening enhancement among the population, these efforts would be a priority in terms of cervical cancer education.

Providing scientifically correct information in a proactive manner, through specific training for health professionals or through a community-based outreach, is the only effective way for health authorities to reassure 
people and ensure good vaccine acceptability (18).

To our knowledge, this review is the first study focusing on anti-HPV vaccine acceptability in the MENA region. One of its strengths is the inclusion of both quantitative and qualitative research studies, which increased the depth and explanatory nature of our findings.

This review focused on different subgroups of the population and did not exclude any category from the analysis. Thus, we enhanced the generalizability of the trends recorded for each subgroup throughout the geographic area of interest. The restriction on language and religion of the enrolled countries was also aimed at enhancing the external generalizability of the results.

One of the limitation of this study is a potential misclassification of demographic data based on the origin of the participants (rural versus urban) since this detail was not always clearly stated in the studies we reviewed. Additionally, not all the studies are consistent regarding their methodologies in the sense that not all the questions of interest were systematically discussed. For example, while some studies assessed level of knowledge and awareness of cervical cancer and HPV, others did not. The same was found for willingness to vaccinate and acceptability of the HPV vaccine. Some studies discussed all themes. This indicates a need for more standardized methods for collecting data in order to provide better insight. Finally, there is a possibility that we missed some eligible studies not identified in the search, or studies that were not published (publication bias).

\section{Conclusions}

To the best of our knowledge, this is the first systematic review of the potential willingness in regard to the introduction of the anti-HPV vaccine in this part of the MENA region. An examination of this area collectively offers an insight into the willingness of the population and the medical staff to receive more information about the virus and its prevention through vaccination. It also revealed the lack of clear recommendations and serious strategies towards anti-HPV vaccine from most of the health authorities of the region.

Knowing the elevated levels of acceptability and willingness to receive the anti-HPV vaccine in the Arab states of the MENA region, health authorities should benefit from this opportunity to provide more information and education for health workers, women/ girls, young people and parents on HPV infection and how to acquire effective protection.

\section{Ackowledgement}

This paper is dedicated to the memory of my wonderful supervisor, Pr Soltani, who recently passed away and who inspired and supervised this project. Without his contribution, support and guidance this would never have been possible.

Funding: None.

Competing interests: None declared.

\section{Connaissance, sensibilisation et acceptabilité en matière de vaccin contre le papillomavirus humain dans les États arabes de la Région du Moyen-Orient et de l'Afrique du nord : analyse systématique \\ Résumé}

Contexte : Les changements de modes de vie rapides induits par la mondialisation ont entrainé des changements de comportements sexuels, en particulier chez les jeunes générations. Ces changements peuvent avoir des conséquences considérables sur la prévalence des maladies sexuellement transmissibles, dont l'infection par le papillomavirus humain (VPH).

Objectif : La présente étude avait pour objectif de procéder à une analyse systématique des publications revues par des pairs portant sur la sensibilisation au vaccin contre le papillomavirus humain (VPH) et son acceptabilité dans les États arabes de la Région du Moyen-Orient et de l'Afrique du Nord.

Méthodes : Une recherche systématique a été effectuée dans deux bases de données électroniques (PubMed et EMBASE) afin d'identifier les études sur la sensibilisation à la vaccination contre le VPH et son acceptabilité dans la région, qui ont été produites entre janvier 2010 et avril 2017.

Résultats : Dix-huit études, menées dans neuf pays, ont été identifiées. L'analyse a montré une connaissance de l'infection par le papillomavirus humain et une sensibilisation au vaccin contre le VPH allant de faibles à modérées. Néanmoins, la plupart des études ont rapporté une acceptabilité du vaccin contre le VPH comprise entre modérée et élevée parmi les sous-populations. D'importants écarts de connaissance du vaccin contre le VPH et de disposition à l'accepter ont été mis en évidence.

Conclusion : Un examen dans la région dans son ensemble offre un aperçu de la disposition de la population générale et des prestataires de soins de santé à bénéficier de davantage d'informations sur le virus et d'une prévention de l'infection grâce à la vaccination. Cette étude suggère que l'acceptabilité des vaccins sera élevée une fois que la question des coûts sera résolue. 


\section{معرفة اللقاحات المضادة لفيروس الورم الحليمي البشري والوعي بها وتقبّلها في الدول العربية لإقليم الشرق الأوسط وشمال أفريقيا: استعر اض منهجي \\ رحاب قمعون

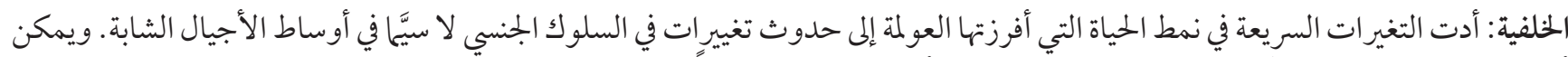

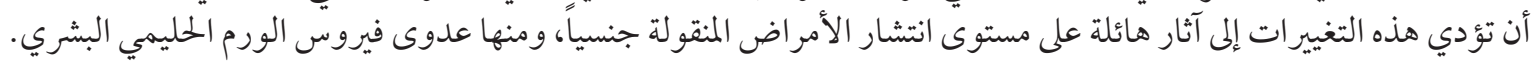

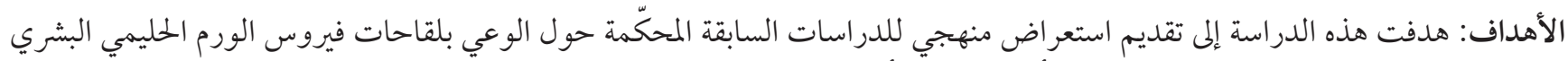

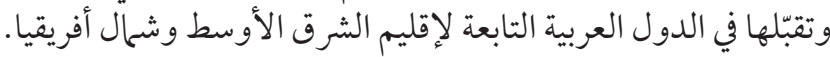

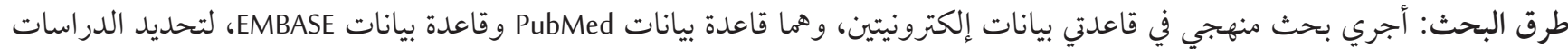

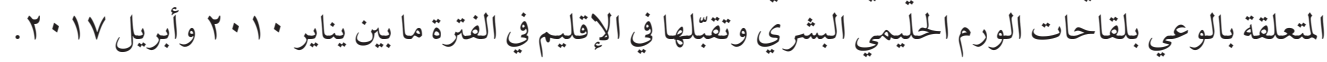

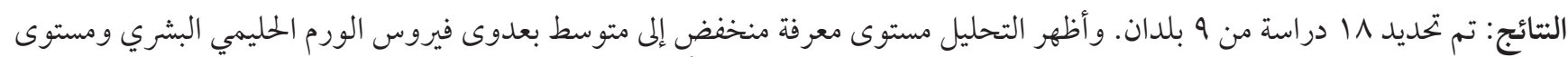

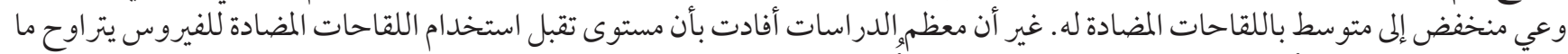

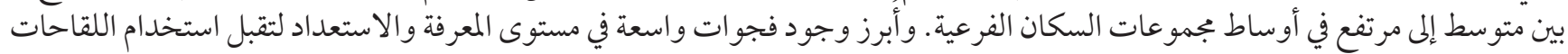
المضادة لفيروس الورم الحليمي البشري.

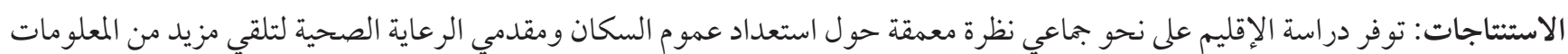

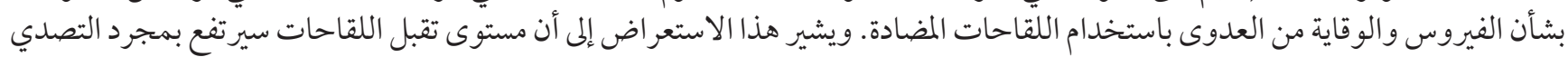
للاهتمامات المرتبطة بتكلفته.

\section{References}

1. El-Kak F. Sexuality and sexual health: constructs and expressions in the extended Middle East and North Africa. Vaccine. 2013 Dec;31(Suppl. 6). PMID:24331819

2. Khodakarami N, Clifford GM, Yavari P, Farzaneh F, Salehpour S, Broutet N, et al. Human papillomavirus infection in women with and without cervical cancer in Tehran, Iran. Int J Cancer. 2012 Jul;131(2):E156-61. PMID:22038830

3. Estimates of worldwide burden of cancer in 2008: GLOBOCAN 2008. Int J Cancer. 2010;127(12):2893-917. PMID:21351269

4. Jemal A, Bray F, Center MM, Ferlay J, Ward E, Forman D. Global cancer statistics. CA Cancer J Clin. 2011;61(2):69-90. PMID:21296855

5. Vaccarella S, Bruni L, Seoud M. Burden of human papillomavirus infections and related diseases in the extended Middle East and North Africa region. Vaccine. 2013 Dec;31(Suppl. 6): G32-44. PMID:24331818

6. Bornstein J. Human papillomavirus vaccine: the beginning of the end for cervical cancer. Isr Med Assoc J. 2007 Mar;9(3):156-8. PMID:17402325

7. Bornstein J. The HPV vaccines--which to prefer? Obstet Gynecol Surv. 2009 May;64(5):345-50.

8. Seoud M. Burden of human papillomavirus-related cervical disease in the extended middle East and north Africa-a comprehensive literature review. J Low Genit Tract Dis. 2012 Apr;16(2):106-20. PMID:22371041

9. Fisher WA, Laniado H, Shoval H, Hakim M, Bornstein J. Barriers to human papillomavirus vaccine acceptability in Israel. Vaccine. 2013 Nov;31(Suppl. 8):I53-7. PMID:24229720

10. Kim JJ, Sharma M, O'Shea M, Sweet S, Diaz M, Sancho-Garnier H, et al. Model-based impact and cost-effectiveness of cervical cancer prevention in the extended Middle East and North Africa (EMENA). Vaccine. 2013;31(Suppl. 6):G65-77. PMID:24331822

11. Seoud M, Vaccarella S, El-Kak F, Sancho-Garnier H, Jumaan AO, Kim JJ, et al. Extended Middle East and North Africa: Summary recommendations for the prevention of human papillomavirus infections and related cancers including cervical cancer. Vaccine. 2013; 31(Suppl. 6):G78-9. PMID:24331823

12. Ortashi O, Shallal M, Osman N, Raheel H. Knowledge, attitude and practice of school nurses in the United Arab Emirates about HPV infection and vaccine. Asian Pac J Cancer Prev. 2012;13(12):6481-4. PMID:23464478

13. Dany M, Chidiac A, Nassar AH. Human papillomavirus vaccination: assessing knowledge, attitudes, and intentions of college female students in Lebanon, a developing country. Vaccine. 2015 Feb;33(8):1001-7. PMID:25597945

14. Mouallif M, Bowyer HL, Festali S, Albert A, Filali-Zegzouti Y, Guenin S, et al. Cervical cancer and HPV: awareness and vaccine acceptability among parents in Morocco. Vaccine. 2014 Jan;32(3):409-16. PMID24188754

15. Ortashi O, Raheel H, Khamis J. Acceptability of human papillomavirus vaccination among male university students in the United Arab Emirates. Vaccine. 2013 Oct;31(44):5141-4. PMID:23965182 
16. Al-Nuaimi NS, Al-Ghas YS, Al-Owais AH, Grivna M, Schneider J, Nagelkerke NJ, et al. Human papillomavirus vaccination uptake and factors related to uptake in a traditional desert city in the United Arab Emirates. Int J STD AIDS. 2011 Jul;22(7):400-4. PMID:21729960

17. Gilmour S, Kanda M, Kusumi E, Tanimoto T, Kami M, Shibuya K. HPV vaccination programme in Japan. Lancet. 2013 Aug;382(9894):768. PMID:23993189

18. Larson HJ1, Smith DM, Paterson P, Cumming M, Eckersberger E, Freifeld CC, et al. Measuring vaccine confidence: analysis of data obtained by a media surveillance system used to analyse public concerns about vaccines. Lancet Infect Dis. 2013;13(7):60613. PMID:23676442

19. Moosa K, Alsayyad AS, Quint W, Gopala K, DeAntonio R. An epidemiological study assessing the prevalence of human papillomavirus types in women in the Kingdom of Bahrain. BMC Cancer. 2014;14. PMID:25466757

20. Shaltout MF, Sallam HN, AbouSeeda M, Moiety F, Hemeda H, Ibrahim A, et al. Prevalence and type distribution of human papillomavirus among women older than 18 years in Egypt: a multicenter, observational study. Int J Infect Dis. 2014 Dec;29:226-31. PMID:25447728

21. Obeidat BR, Amarin ZO, Alzaghal L. Awareness, practice and attitude to cervical Papanicolaou smear among female health care workers in Jordan. Eur J Cancer Care (Engl). 2012;21(3):372-6. PMID:22050559

22. Berraho M, Fakir S El, Abda N, Mathoulin-Pelissier S, Nejjari C. [HPV and cervical cancer: knowledge and practices of physicians in Fez]. Sante Publique Vandoeuvre--Nancy Fr. 2013 Jun;25(3):351-7. [in French] PMID:24007911

23. Selmouni F, Zidouh A, Nejjari C, Bekkali R. Acceptability of the human papilloma virus vaccine among Moroccan parents: a population-based crosssectional study. East Mediterr Health J. 2015 Aug;21(8):555-63. PMID:26446526

24. Zouheir Y, Daouam S, Hamdi S, Alaoui A, Fechtali T. Knowledge of human papillomavirus and acceptability to vaccinate in adolescents and young adults of the Moroccan population. J Pediatr Adolesc Gynecol. 2016 Jun;29(3):292-8. PMID:26612116

25. AlObaid A, Al-Badawi IA, Al-Kadri H, Gopala K, Kandeil W, Quint W, et al. Human papillomavirus prevalence and type distribution among women attending routine gynecological examinations in Saudi Arabia. BMC Infect Dis. 2014;14:643. PMID:25496614

26. Hussain AN, Alkhenizan A, McWalter P, Qazi N, Alshmassi A, Farooqi S, et al. Attitudes and perceptions towards HPV vaccination among young women in Saudi Arabia. J Fam Community Med. 2016 Dec;23(3):145-50. PMID:27625580

27. Al-Darwish AA, Al-Naim AF, Al-Mulhim KS, Al-Otaibi NK, Morsi MS, Aleem AM. Knowledge about cervical cancer early warning signs and symptoms, risk factors and vaccination among students at a medical school in Al-Ahsa, Kingdom of Saudi Arabia. Asian Pac J Cancer Prev. 2014;15(6):2529-32. PMID:24761859

28. Al-Shaikh GK, Almussaed EM, Fayed AA, Khan FH, Syed SB, Al-Tamimi TN, et al. Knowledge of Saudi female university students regarding cervical cancer and acceptance of the human papilloma virus vaccine. Saudi Med J. 2014 Oct;35(10):1223-30. PMID:25316467

29. Sait KH. Knowledge, attitudes, and practices regarding cervical cancer screening among physicians in the Western Region of Saudi Arabia. Saudi Med J. 2011 Nov;32(11):1155-60. PMID:22057604

30. Alsaad MA, Shamsuddin K, Fadzil F. Knowledge towards HPV infection and HPV vaccines among Syrian mothers. Asian Pac J Cancer Prev. 2012;13(3):879-83. PMID:22631665

31. Almobarak AO, Elbadawi AA, Elmadhoun WM, Elhoweris MH, Ahmed MH. Knowledge, Attitudes and practices of Sudanese women regarding the pap smear test and cervical cancer. Asian Pac J Cancer Prev. 2016;17(2):625-30. PMID:26925654 